\title{
Evaluation of sustainable vernacular architecture and settlements in Yunnan
}

\author{
L. Wang \& Z. Yang \\ School of Urban Design, Wuhan University, P. R. China
}

\begin{abstract}
The settlement and vernacular architecture in Yunnan can be imagined as a living organism which is the outcome of centuries of optimization of topography adaption, climate consideration, material use, construction techniques, etc. The environment and the multiple forms of Yunnan traditional dwellings reflect the balanced development of residential houses, cultural background and natural ecology, forming regional context and system. This paper aims to explore and evaluate sustainable vernacular architecture and settlement from a settlement layout, architecture form and natural architecture materials so as to put forward the sustainable perspective. It also can be taken as an example for modern building and landscaping design.
\end{abstract}

Keywords: vernacular architecture, settlement, sustainable perspective.

\section{Introduction}

Yunnan is located in the southwest of China. It is a large province boasting strong regional features, of various types and national characteristics with traditional settlements. The whole province has 51 minority nationalities, eight autonomous regions, among which 26 minority nationalities have a population of over 5000 and stable distributions. The Bai, Hani, Dai, Naxi, Lishu, Lahu, Wa, Jingpo Pumi, Dengang, Dulong, Jinuo nationalities are unique in Yunnan. They are rare worldwide also.

Being mountainous and isolated, Yunnan falls behind many places in China. However, it is the very development lag that many small towns and villages in Yunnan collectively contain some of the best-preserved and aesthetically delightful traditional architecture as well as settlements with minority nationalities in all of China. This is the precious architecture and culture heritage 
of historical, cultural, scientific, artistic value and tourism resource value. They provide the advantageous research conditions for the ecological characteristics of traditional dwellings.

This paper aims to explore and evaluate sustainable vernacular architecture and settlement from a settlement layout, architecture form and natural architecture materials so as to put forward the sustainable perspective. It also can be taken as an example for modern building and landscaping design.

\section{Harmonious settlement space}

The lay of the land of Yunnan inclines from northwest to southeast, the altitude decreasing from more than 7600 to $76 \mathrm{~m}$. This area is characterized by a segmented topography. There can be a $1000-3500 \mathrm{~m}$ difference in elevation between the valley floor and the jutting mountain tops that surround it. Various climatic zones affected by topography, altitudes and latitudes are distributed according to season and location forging a complex tri-dimensional climatic character [1] (Figure 1).

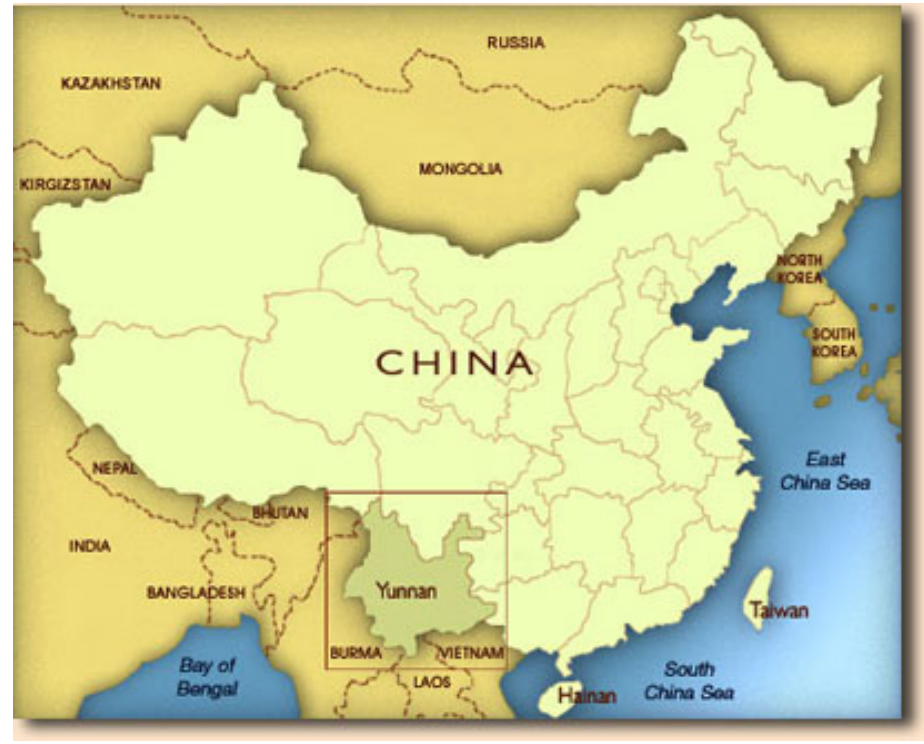

Figure 1: Location of Yunnan.

In ideology, Chinese culture represents entirety and harmonious dialectical unification. The view of nature represents entirety and harmonious dialectical unification, easing from more than 7600 to $76 \mathrm{~m}$. This area experienced a long and complex transformation process, to form a unique regional culture and settlement landscape, not only to fully demonstrate the harmonious coexistence of man and nature, but also to provide a human a great difference from city life and living place. 


\section{1 "FengShui" theory in harmonious settlements}

"FengShui" is a word which Chinese people seek for an ideal living environment. Recent scientific research shows that the site selection which has been influenced by "FengShui" theory is rather scientific and rational.

A good FengShui settlement can be described as an expansive land area that is embraced by mountain and hills. It should be provided with six basic conditions: back mountains; embraced by multiple layers of surrounding hills; river or stream at the front with a lake or pond nearby; buildings facing southward orientation; having a flourishing forest and abundant natural resources in the surrounding environment and placing architectural symbols such as a pagoda, bridge, pavilion and memorial gate in varied positions [2] (Figure 2).

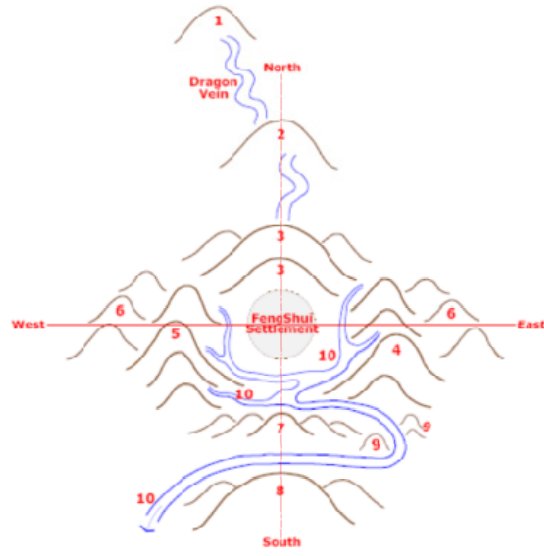

1 Ancestral Mountain

2 Family Mountain 3 Principal Mountain 4 Left Hill

5 Right Hill

6 Guardian Hill

7 Near Front Hill

8 Far Front Ilill

9 Water Mouth Hill 10 Water Source

(river, stream, lake or pond)

Figure 2: $\quad$ Prototype of ideal FengShui environmental model.

We can see from Figure 1 that this organic combination between seeking a settlement pattern with the natural environment shows that the human living space has a profound enlightenment to ecological planning and the environment crisis. In Yuanyang County, Yunnan Province, the relationship between settlements and the natural environment is very harmonious. Tu-zhang dwellings were built along sunny hill slopes, distributed along hillside and layer upon layer. Spring water from the mountain flows into the village across every house. Green foliage, golden bamboo and brown loquat are extensively planted. Furthermore, around the village, the forest is luxuriant and strongly fragrant. Terraced fields before the village extend to the foot of the hill.

According to "FengShui" theory villagers put advantageous natural conditions into settlements and eliminate the adverse effect by layout. For example, the settlement of the Bai nationality is usually located on the east of Cang Shan, facing west in order to avoid leading wind direction and to obtain good sunshine. In addition, people draw water sources from the mountain to the Dali and Lijiang thus diverting gradually every house in the streets. 


\subsection{Three types of harmonious settlements}

The traditional settlement of Yunnan reinforces space texture of topography according to the natural development of its topography and it displays an integral and unified growth relationship. There are three types of harmonious settlements in Yunnan: the growth type settlement along a mountainous contour line, lineshape growth settlement and group growth type settlement. The growth type settlement along a mountainous contour line is that a great number of mountainous settlements are arranged and extended in parallel along the contour line. The layout of settlement is free and flexible to develop, sometimes along the contour line, sometimes perpendicular to the contour line, sometimes deflecting different angles (Figure 3).
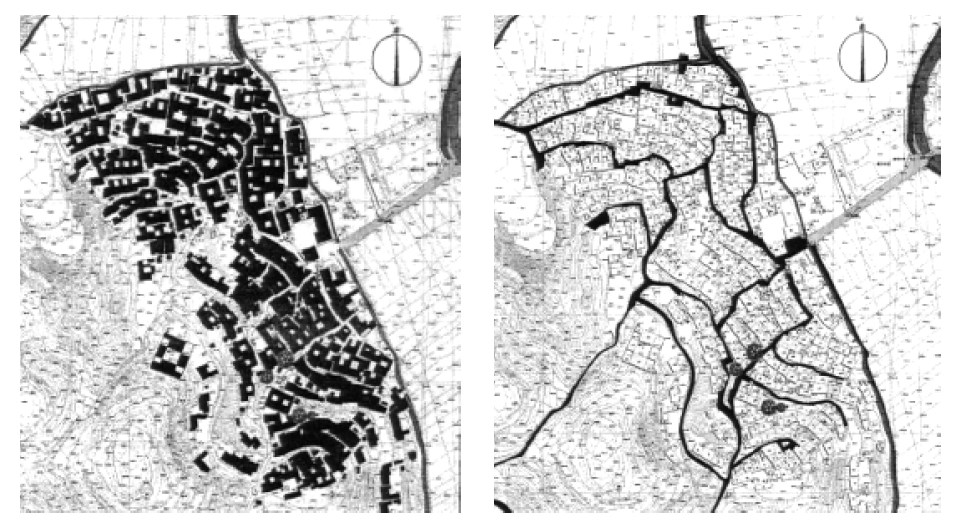

Figure 3: The texture of a growth type along a mountainous contour line.

The line-shape growth settlement is based on the geographical features of Yunnan. It generally extends or grows gradually along rivers one side or both sides, taking the linearity as its intrinsic order. The direction of dwellings goes with the river system. The variation of street space is rich and natural (Figure 4).

The group growth type settlement is not the simple combination and overlap. The layout presents a tendency of group composition and development. Even though some of the minority settlements have a more rational intrinsic order, such as a precise road system, village center and village gate, overall, the growth of the settlement complies with natural factors such as micro-topography and forest farmland. It appears as a natural street skeleton and develops between order and randomness (Figure 5).

Based on topography, the traditional settlement takes advantage of all kinds of natural factors such as wind direction, daylight, air and hydrology to build a harmonious settlement layout. Some massed settlements such as the "Thousand foot landing room" of the Lishu settlement, the "Tu-Zhang House" (earthrammed house) settlement, are adapted to topography, effectively realize occupying cultivated land and natural green space as little as possible in order to keep massive farmlands, production lands and an ecological barrier. 

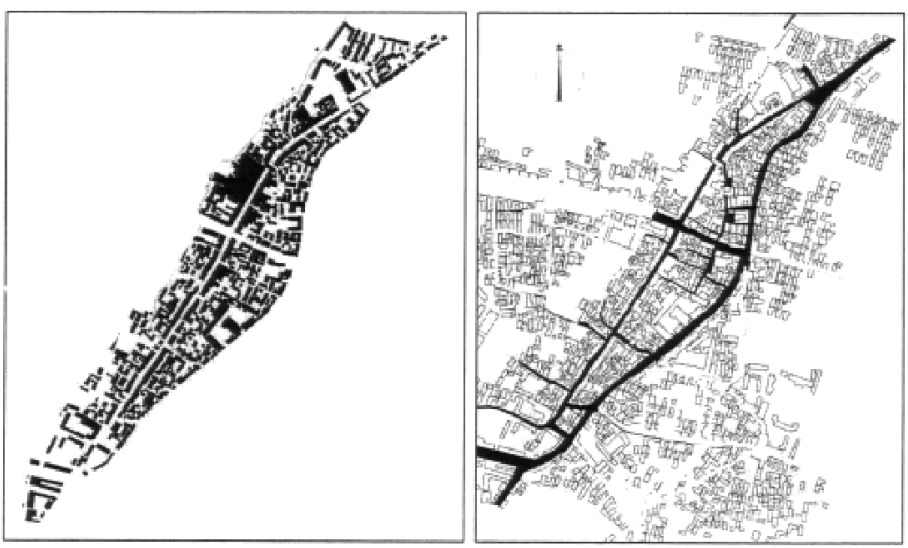

Figure 4: The texture of the line-shape growth settlement.
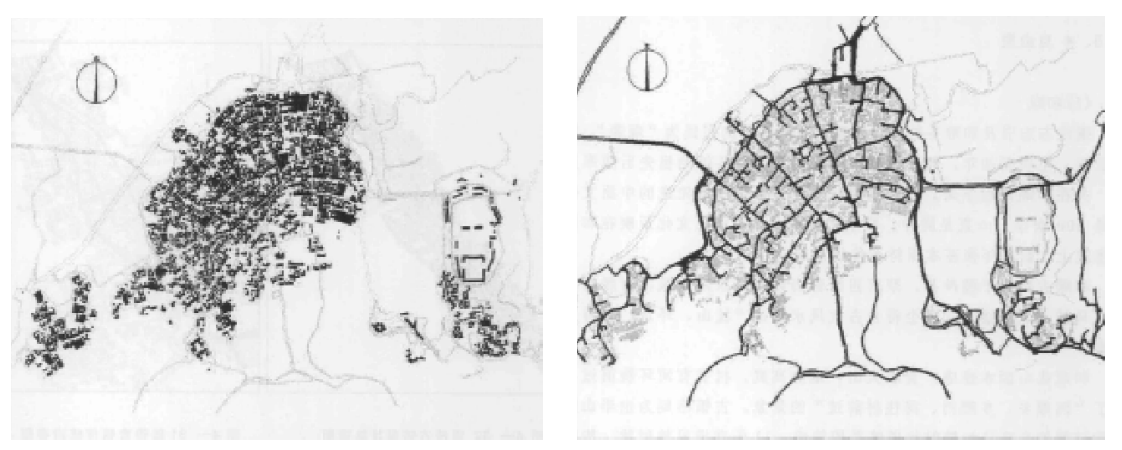

Figure 5: The texture of a group growth type settlement.

\section{Architecture form}

Vernacular architecture is considered an ideal way to understanding design, as an example of simplicity and the conservation of resources, specifically energy. Sustainability in architecture plays an important role in today's lives.

\subsection{Adaption to climate}

Vernacular architecture refers to structures built using locally available materials in a functional style devised to meet the needs of common people in their time and place. Most of the vernacular architecture responds to the regional climate [3]. As different climates require different architectural responses, those traditional dwellings in Yunnan developed through fifty years or even centuries 
and formed many original and interesting styles in order to meet various necessities, such as the stilted house, the Tu-Zhang house, the courtyard house, etc. All architecture forms are in correct logical relation with climates and they present adaptability to climate and environment (Figure 6).

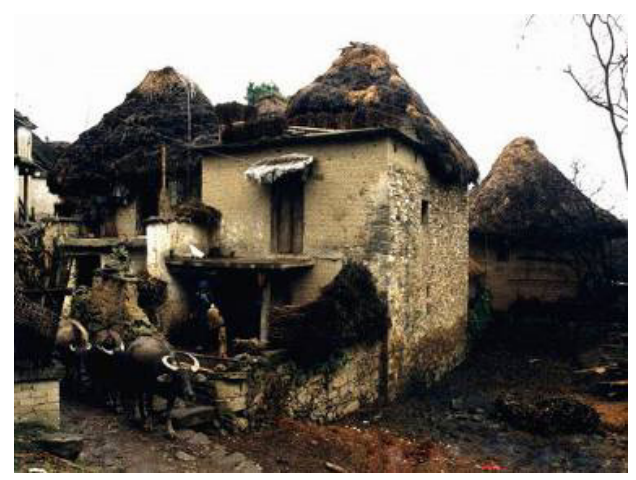

Figure 6: Mushroom house in Yuanyang County.

For example, the stilted house which is a kind of pure wooden building and belongs to dry-column for residential construction is generally in hot, humid and rainy weather conditions. In the book "the History of Chinese Ancient Architecture" Liu Dunzhen tells that the minorities who live in sub-tropical regions such as Guangxi, Guizhou, Yunnan, Taiwan, etc., use the layer stilted residence in order to prevent moisture, and to ventilate and achieve good daylight (Figure 7).

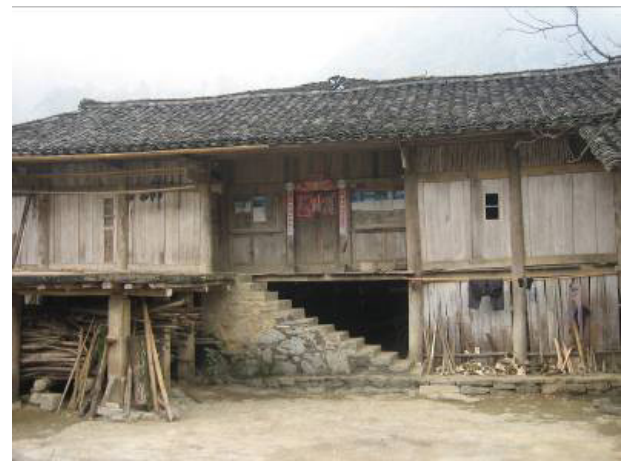

Figure 7: The stilted house in Yunnan.

In Dali, most of the main rooms of the courtyard house are set to face south. The southern wall of the main room mainly has wide windows and doors opening to the courtyard, in order to receive southern sunshine and a warm breeze. 
The Dai ethnic minority mostly live in the river valleys in Xishuangbanna and Ruili which are characterized by low terrain and abundant rainfall. The bamboo buildings use wood as the framework of the houses and bamboo is taken as the purlin, rafter, floor, wall, ladder, etc. It is conducive for avoiding insects, snakes and beasts; the buildings are also damp-proof and well ventilated.

\subsection{Passive solar energy}

A solar passive house makes effective use of solar radiation to warm up indoors in winter for heating and to block out this radiation in summer for cooling and provides better indoor illumination through lighting [4]. Yunnan has abundant solar energy resources due to the clear sky resulting from the high altitude. According to statistics, $90 \%$ of the area of Yunnan has an annual radiation above $5000 \mathrm{MJ} / \mathrm{m}^{2}$ and an annual sunshine duration above $2000 \mathrm{~h}$.

Usually, the courtyard is a common and characteristic form of vernacular architecture in warm and humid climatic zones, such as Kunmin, Dali, Jianshui, Lijiang, etc. It serves as a collector of cool air at night and a source of shade in the daytime [5]. The yards in Yunnan courtyard architecture are various. In a broad sense, it can be formed by different types: "loujiao skywells", "Huge skywells" or the "veranda" in the Naxi and the Bai vernacular architecture. Generally, the proportion of width to depth is approximately 3:2 of skywell in the courtyard architecture. The open courtyard in Dali and Lijiang is to maximize sunlight and solar gain. Furthermore, these courtyards play an important role in natural ventilation and enhanced air circulation. It is also found that the orientation of houses is east-west direction and south facing. This is the preferred direction because the courtyard receives maximum sun.

Transition spaces in terms of verandas, corridors, etc., as a part of yard space, are modified according to the needs in summer and winter months to maintain comfortable conditions inside the building. For example, the dwelling of the Dai nationality in Xishuangbanna has a spacious partly-opened porch, $>3 \mathrm{~m}$ width, its area is $20-30 \mathrm{~m}$. The Dai dwelling in Ruili has a $2-2.4 \mathrm{~m}$ porch in front of the principal room.

The narrowed skywell of "yikeyin" is used for heat preservation and wind prevention, while the small skywell of "tu-zhang house" is good for ventilation and exhaust.

\subsection{Plantation and water system}

The courtyard provides the much needed space and satisfies the social and cultural needs. Moreover, it provides the necessary space for post harvesting activities. "Zhaobi" is the important decoration in the courtyard. Functionally, it can be reflective of sunshine, so that the yard becomes brighter, as well as blocking the mountain breeze. In addition, plantation and the water system are important ecological characteristics in Yunnan traditional houses, especially in courtyard houses. They are composed of a pool, a well, a pump and green areas that are located in the courtyard of the houses. These elements not only meet the 
requirements of the house, but also provide a space to enjoy the natural environment.

There are all kinds of flowering trees and shrubs in Yunnan residential houses. In Lijiang and Jianshui, trees and flowers are important parts in courtyards. People are so fond of gardening that every family keeps a garden in their courtyard where you can find orchids, cuckoos, peonies, bamboo, etc.

Water is the origination of life. In order to build ideal living environments after site selection of villages, people usually rebuild the surrounding environment. The water system becomes the focus of rebuilding. For example, the old town of Lijiang is a city which depends on water for existence and water is just like its blood. The city brings spring water to the town's residents. At the start of the system, primary springs emerge from a carbonate rock aquifer and feed into Black Dragon Pool just north of the town. It was these natural springs that led the Naxi to this area in the first place. From Black Dragon Pool, water follows the Jade River and then divides into three canals to provide water to Lijiang. Dictated by Naxi tradition, the canal water was used for drinking and cooking in the early morning, for cleaning vegetables in the late morning and for washing clothes and household items in the afternoon. The layout of street in town is free and regular without pattern. The street extends and winds along the water system.

In summer, the water can moisten the air and adjust air temperature. Furthermore, it is common in large-scale courtyard houses that fountains and pools can be made.

\subsection{The technology of architecture}

It is stressed that the vernacular technologies have been devised uniquely to the region where people lived to cope with the severe climate by inventing various devices without resorting to fossil fuels, thus the form of vernacular architecture representing a regionalism of their own.

\subsubsection{Various roofs}

The size of roof slope shows the distribution of rainfall. In dry-cold or dry-hot climate, the construction of roof is aimed at heat-resistance and keeping warm. For example, the "Tu-Zhang House" is at dry heat area, therefore, the thickness of the roof is $25 \mathrm{~cm}$ up and down by using a three layered structure. While in high and cold mountainous areas, the flat roof of the "Tu-Ku House" of the Zang nationality is characterized by cold-resistance and keeping warm. The thickness of the roof is almost $30 \mathrm{~cm}$ by using a five layered structure. In the wet-hot climate, the structure of the roof emphasizes ventilation and shading. For example, eaves were seen frequently in hot climates on dwellings with nonmassive walls suggesting they are used for cooling the structure. In Xishuangbanna the roof of the Dai nationality dwelling occupies half of the whole traditional house. Steep roofs and overhang on windows are not only good for draining rainwater but also provides shading. 


\subsubsection{Outer protective structure}

The outer protective structure in dry hot and dry cold regions is aimed at heatresistance and keeping warm. The most common effective structure is to strengthen heat storage. In wet-hot areas, the construction and materials are good for air permeability. For example, the planks and bamboo are used as an outer protective structure in the residential house of the Dai nationality. There are some seams between planks and the bamboo, furthermore, the juncture between outer protective structure and roof sets aside opening, making air permeable. The houses with bamboo and planks are sturdy and dry inside the room due to good ventilation - wind can blow in the room through the slots of bamboo strips. Therefore, they are cool inside the room even in hot summer days. In addition, the residential houses of the $\mathrm{Wa}$ and Suli nationality use bamboo as an outer protective structure. However, in order to avoid suffering from frequent minor earthquakes, local builders in Da li have developed a functional and flexible technique of timber structure which is "wooden lock" and the "enclosure lintel" to improve earthquake resistance.

\subsubsection{Windows}

By optimizing the position and size of window openings, people make the dwelling to adapt to the climatic environment. In temperate climate areas, people reduce the window openings outside the wall, enlarging them inward courtyard in courtyard architecture. For example, the courtyard house in Dali usually has only few small windows. Most of the main rooms are set to face south. The southern wall of the main room usually has wide windows and doors opening to the courtyard, in order to receive southern sunshine and a warm breeze [6]. In dry hot or dry cold climate areas, people reduce the window openings or have them facing east. For an instance, the high windows of "Tu-Zhang House" and bunker of the Zang nationality are not only well-ventilated, but also get the maximum use out of light.

However, in wet-hot climate areas, opening window widely and using bamboo as outer protective structure instead of opening window are needed.

\section{Sustainable architecture materials}

Yunnan has an abundant forest resource due to its unique climatic and topographic conditions [7]. The form of sustainable environment is based on the perfect usage of ecological material. The vernacular architecture in Yunnan is built with local materials, generally from bamboo, artificial clay, pebble, wood, soil or stone.

The materials, considering their lightweight and high efficiency in flexibility, on the basis of physical conditions, and resisting against the heat conductivity factor, are some of the best items which have been used in Yunnan nationality architecture. On the other hand, using the materials which are originally taken from nature and the local materials can be the positive point for this type of architecture. 
They are products to adapt natural environment and are of physical characteristics of adapting to the weather condition [8]. For economic and traffic reasons, the use of local materials in Yunnan traditional houses is very diverse and flexible [9]. They not only reduce building costs, but also obtain good material performance. For instance, due to the availability of wood in the northwestern mountainous area, the traditional log houses are built with timber frames for the walls, floors and roof. Log walls provide good insulation in cold weather and they are solid to make for a good anti-seismic structure. The TuZhang houses which are made of rammed earth can not only preserve and insulate heat, but also is low-cost.

In addition, those local materials adapt to the local cool climate. While in Xishangbanna, the wet-hot weather is good for bamboo growing, therefore, the Dai eats bamboo, live in bamboo and use bamboo. The bamboo house becomes a major symbol in Xishuangbanna.

\section{Conclusions}

To conclude, on the one hand, the traditional residences in Yunnan province meet the requirements of amenity by adaptability to the environment. On the other hand, the constructing of traditional houses is obtained from the aboriginal forest. It adds more pressure on our country's limited natural forest resource. With strengthening the protection for the country's natural forest, the material base of wood-structure system is in great peril. Such is the situation that traditional houses are facing the problem of resource shortage of wood materials [10]. Therefore, corresponding technical modification and optimization measures for construction technology, developing local materials and extending the new Solar Energy Technology to improve people's living environment and dig the features of regional architecture. Furthermore, it can promote the development of ecological architecture.

With the development of economy, mankind is facing a severe test in solving the problems of environment and development. The sustainable living environment becomes a great research project. The contemporary architect should resolve the conflict between the comfortable living environment and energy saving and ecological environment protection. Chinese traditional architecture creates the environment that is harmonious coexistence between man and nature with the special geographic position and the natural environment to build houses. Therefore, we should pay more attention to the natural ecological features and institutional mechanism to realize how to combine regional climate, natural resources and ecological environment.

\section{References}

[1] Wang Renping, Cai Zhenyu, An ecological assessment of vernacular architecture and of its embodied energy in Yunnan, China, Building and Environment, 41 (2006) 687-697. 
[2] Zhong Zhiqin, Dr. Ceranic, Boris, FengShui, A Systematic Research of Vernacular Sustainable Development in Ancient China and its Lessons for Future, $7^{\text {th }}$ UK CARE Annual General Meeting, 2007.

[3] R. Albatici, Elements and strategies for sustainable intervention in the residential building sector: a case study. Indoor and Built Environment, 18 (5), pp. 447. 2009.

[4] Nayak, J.K., Prajapati, J.A., Handbook on Energy Conscious Buildings. Solar Energy Centre, Ministry of Non-conventional Energy Sources, Government of India, New Delhi, 2006.

[5] A. Aldawoud, Thermal performance of courtyard buildings. Energy and Buildings, 40(5), pp. 906-910, 2008.

[6] Voeller Elizabeth, Fitzpatrick Joseph, Renewing an environmental ethic for the Naxi of Lijiang, China, World Lake Database (ILEC).

[7] Li Zhimin, Tang Runsheng, Xia Chaofeng, Luo Huilong, Zhong Hao, Towards green rural energy in Yunnan, China, Renewable Energy (30), pp. 99-108. 2005.

[8] Lindsay Asquish, Marcel Vellinga, Vernacular Architecture in the TwentyFirst Century Energy, Education and Practice. London: Taylor \& Francis, 2006.

[9] Jiang Gaohuan, The cultural of Yunnan nationality residential house, Kunming: the press of Yunnan University, 1997.

[10] Bai Wenfeng, Structure Renewal and Sustainable Using of Natural Building Materials on Yunnan Folk Houses. [D], Tsinghua University, 2009. 